\title{
PREDICTION OF TAPPING FORCES AND TORQUE FOR 16MnCr5 ALLOYED STEEL
}

\author{
Mihajlo Popović, Antun Stoić, Ljubodrag Tanović
}

Preliminary note

The paper presents cutting tools geometry analysis for the active part of straight fluted taps and a prediction model for tapping forces and torque. To derive the relation between the angles that define the geometry of the tools, the orientation matrices for taps coordinate systems are defined. Along with analytical model setup, the taps are additionally modelled in CAD package based on main parameters taken from the external database. The cutting coefficients for material combination for the workpiece $(16 \mathrm{MnCr} 5)$ and tool (HSS-E, EMo5Co5) were identified using the orthogonal cutting mechanics which is needed for prediction procedure. Proposed prediction model for tapping forces and torque of the machine tap, in addition to the effects of the major cutting edges, includes an action from minor cutting edges, too. Results of experimental verification for the proposed procedures and models are presented in this paper.

Keywords: CAD; cutting forces; prediction; tool geometry; tapping

Predviđanje sila i momenta urezivanja navoja u legiranom čeliku $16 \mathrm{MnCr} 5$

Prethodno priopćenje

U radu je prikazana analiza geometrije aktivnog dijela rezne oštrice ureznika sa ravnim žljebovima i model za predviđanje sila i momenta urezivanja navoja. Da bi se dobio odnos između kutova koji definiraju geometriju alata, određene su orijentacijske matrice za koordinatne sustave ureznika. Pored postavljanja analitičkog modela, ureznici su modelirani u CAD paketu s glavnim parametrima iz vanjske baze podataka. Koeficijenti rezanja za kombinaciju materijala obratka (16MnCr5) i alata (HSS-E, EMo5Co5) identificirani su pomoću mehanike ortogonalnog rezanja. Predloženi model za predviđanje sila i momenta urezivanja strojnim ureznikom, osim učinka glavnih reznih oštrica, uključuje također i akcije pomoćnih oštrica. Prikazani su rezultati eksperimentalne provjere predloženih postupaka, kao i usporedba s predviđenim vrijednostima sila i momenta.

Ključne riječi: CAD; geometrija alata; predviđanje; sile rezanja; urezivanje navoja

\section{Introduction}

Metal cutting is considered as one of the most important methods for material removing in the production of mechanical components. The prediction of cutting forces acting on the workpiece is essential for solving several important issues: estimation of the power of a machine tool; estimation of the straining actions that must be resisted by the machine tool components, jigs and fixtures; evaluation of the significance of various parameters of cutting forces; evaluation of the performance of new workpiece materials, tool materials, etc. with respect to machinability [1].

All cutting operations share the same principles of cutting mechanics, but their geometry and kinematics are different. The first step in the prediction of forces acting on a cutting tool is to consider a relatively simple orthogonal cutting process in which the cutting edge is perpendicular to the cutting speed and the deformation occurring in the plane. The results of this analysis are used as a base for the development of a model for a much more general case of oblique cutting, where the edge is angled to the cutting speed [2].

This paper is focused to the prediction of tapping forces and torque.Tapping is a common operation used to produce internal threads in the predrilled hole by means of special tool, named the tap. This is one of the more demanding machining processes. A tap is a cutting tool with very complex geometry.

The reference survey shows that the number of papers on tapping issues is rather small, and consequently, the number of models proposed for specific cutting geometry problems is weak as well.

For several decades, it has remained troublesome and costly due to various process failures such as tap breakage, oversized and undersized threads, and burrs at the threaded holes entry and exit [3].

Armarego [4] presented predictive modelling of various technological performance measures for the wide spectrum of machining operations used in practice. He has shown that the cutting process for the straight flute taps could be represented as a series of elemental single edge oblique cuts on each active cutting edge at the tap chamfer end.

Cao and Sutherland [5] developed a mechanistic model for tapping torque and axial force prediction. It is shown that the total tapping load consists of a load resulting from the chip formation and tool flank friction, and a chip packing load, random in nature, resulting from chip clogging in the flute.

Dogra et al. [6] analyzed a mechanistic torque and thrust model for the tapping process. The basic concept involved in that model is that the elemental cutting and thrust forces acting on each tooth are proportional to the uncut chip area. The proportionality constant is determined for a given tool workpiece combination and in a given cutting range by fitting experimental data through drilling experiments used for calibration.

Armarego and Chen [7] and Chen and Smith [8] studied computer-aided predictive models for force and torque in machine tapping operations, based on Armarego's "Unified-Generalised Mechanics of Cutting Approach" for optimizing the generation and use of taps. The results confirm the validity and generic nature of the unified-mechanics of cutting approach.

In order to avoid tap breakage and low threads quality, it is important to obtain a reliable model for force and torque prediction. In their studies, many authors considered only the geometry and cutting action of the major tap cutting edges (Fig. 1, detail "A"). This paper 
introduces the influence of tap minor edges as additional effect to the major ones. The content is structured as follows:

Section 2 of this paper describes the procedure to identify straight fluted tap geometry at arbitrary point on the cutting edge, tap minor edges and chamfer angle influences.

Section 3 describes the process of tap geometry formation in CAD and MATLAB program which is used to identify position and orientation of each elementary edge.

Section 4 includes the force and torque prediction procedure that considers major and minor edges influence, and prediction results. This procedure is illustrated by an example of prediction for tapping $16 \mathrm{MnCr} 5$ alloyed steel workpiece material with M10 straight fluted machine tap. Further, experimental results and comparison with the predicted values are shown.

\section{Straight fluted taps geometry}

The tool-in-hand and the tool-in-use reference system of planes can be defined for any tool. The tool-in-hand geometry includes a set of geometric elements, which are defined through the tool drawing, used in manufacturing, sharpening or measurement of the tool. The tool-in-use geometry works with real or effective geometric elements of cutting tools, which appear in the cutting operations [9].

Fig.1 shows the tool-in-hand and the tool-in-use geometry of the cutting tool part of machine tap with three straight flutes, with the nominal diameter $D$, the tool back rake $\gamma_{\mathrm{p}}$ and the tool cutting edge angle $\kappa_{\mathrm{r}}$, at arbitrary selected point 0 on the cutting edge.

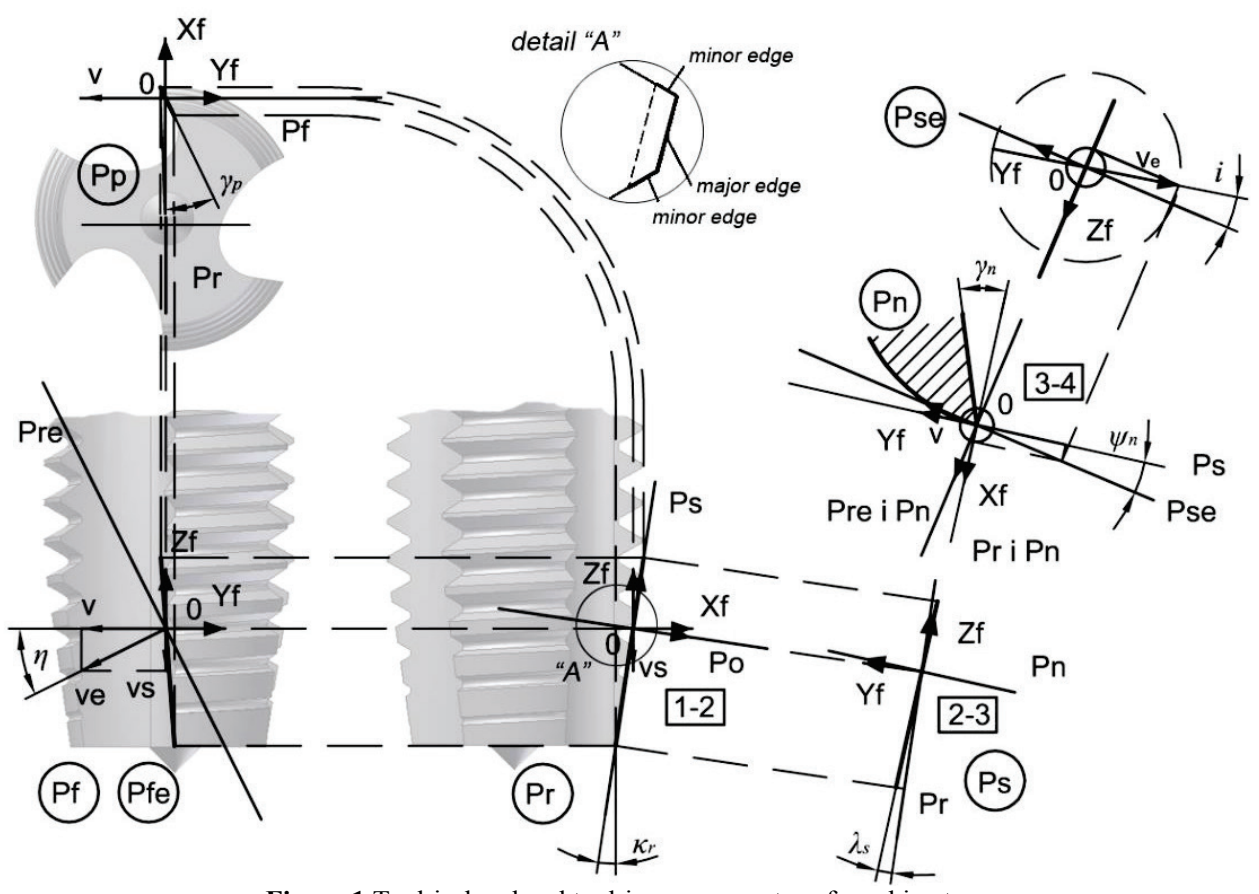

Figure 1 Tool-in-hand and tool-in-use geometry of machine tap

Projection of the cutting edge is shown in the plane $P_{r}$ which is normal to cutting speed $v$ at selected point. Assumed working plane $\mathrm{P}_{\mathrm{f}}$ contains the cutting speed and feed speed. The cutting edge is approximately a straight line due to the small length of cut and rake angle. The cutting edge is inclined at approximately the chamfer angle $\kappa_{\mathrm{r}}$, to the plane $\mathrm{P}_{\mathrm{f}}$ as shown in the plane $\mathrm{P}_{\mathrm{r}}$.

Conventions for the description and presentation of the coordinate system and the indexing system of the transformations are from the theory of computer graphics and modelling systems of solids, and are also used in robot manipulation problems [10].

An arbitrary point in the space $\mathrm{P}$, can be presented with the position vectors with respect to a variety of coordinate systems, so for coordinate systems in which the origin coincides [10]:

${ }^{1} \boldsymbol{p}={ }_{2}^{1} \boldsymbol{R} \cdot{ }^{2} \boldsymbol{p}$, then ${ }^{2} \boldsymbol{p}={ }_{2}^{1} \boldsymbol{R}^{-1} \cdot{ }^{1} \boldsymbol{p}={ }_{2}^{1} \boldsymbol{R}^{\mathrm{T}} \cdot{ }^{1} \boldsymbol{p}$, because the inverse of an orientation matrix, $\boldsymbol{R}$, is the same as its transposed matrix.

Based on Fig. 1, the switch from the tool-in-hand coordinate system " $\mathrm{f}$ " defined with the basic planes $\mathrm{P}_{\mathrm{r}}, \mathrm{P}_{\mathrm{f}}$ and $P_{p}$, labelled as "1", into the tool-in-use system "4" defined with planes $\mathrm{P}_{n}, \mathrm{P}_{\mathrm{se}}$ and their normal plane that contains intersection $\mathrm{P}_{\mathrm{re}} \cap \mathrm{P}_{\mathrm{n}}$, requires three orientation matrices:

$$
\begin{aligned}
& { }_{2}^{1} \boldsymbol{R}=\boldsymbol{R}_{y, \kappa_{\mathrm{r}}}=\left[\begin{array}{ccc}
\cos \kappa_{\mathrm{r}} & 0 & \sin \kappa_{\mathrm{r}} \\
0 & 1 & 0 \\
-\sin \kappa_{\mathrm{r}} & 0 & \cos \kappa_{\mathrm{r}}
\end{array}\right], \\
& { }_{3}^{2} \boldsymbol{R}=\boldsymbol{R}_{x, \lambda_{\mathrm{s}}}=\left[\begin{array}{ccc}
1 & 0 & 0 \\
0 & \cos \lambda_{\mathrm{s}} & -\sin \lambda_{\mathrm{s}} \\
0 & \sin \lambda_{\mathrm{s}} & \cos \lambda_{\mathrm{s}}
\end{array}\right], \\
& { }_{4}^{3} \boldsymbol{R}=\boldsymbol{R}_{z, \psi_{\mathrm{n}}}=\left[\begin{array}{ccc}
\cos \psi_{\mathrm{n}} & -\sin \psi_{\mathrm{n}} & 0 \\
\sin \psi_{\mathrm{n}} & \cos \psi_{\mathrm{n}} & 0 \\
0 & 0 & 1
\end{array}\right],
\end{aligned}
$$


where $\kappa_{\mathrm{r}}$ denotes the chamfer angle, $\lambda_{\mathrm{s}}$ is the angle of inclination and $\psi_{\mathrm{n}}$ is the angle between the cutting edge planes in the tool-in-hand $\left(\mathrm{P}_{\mathrm{s}}\right)$ and tool-in-use $\left(\mathrm{P}_{\mathrm{se}}\right)$ geometry, measured in the normal plane $\mathrm{P}_{\mathrm{n}}$. In the coordinate system "4", oblique cutting is identified using the results obtained by the orthogonal cutting experiments.

Coordinates of the end point of the resultant cutting velocity vector $v_{\mathrm{e}}$ in the first (plane $\mathrm{P}_{\mathrm{f}}$ ) and the last coordinate system (plane $\mathrm{P}_{\mathrm{se}}$ ) according to Fig. 1, are known:

$$
\begin{aligned}
& { }^{1} \boldsymbol{p}=-v_{\mathrm{e}}\left[\begin{array}{lll}
0 & \cos \eta & \sin \eta
\end{array}\right]^{\mathrm{T}} \\
& { }^{4} \boldsymbol{p}=-v_{\mathrm{e}}\left[\begin{array}{lll}
0 & \cos i & \sin i
\end{array}\right]^{\mathrm{T}},
\end{aligned}
$$

where $\eta$ represents the resultant cutting speed angle and $i$ is the oblique angle. From the expression:

$$
{ }^{1} \boldsymbol{p}={ }_{2}^{1} \boldsymbol{R} \cdot{ }_{3}^{2} \boldsymbol{R} \cdot{ }_{4}^{3} \boldsymbol{R} \cdot{ }^{4} \boldsymbol{p},
$$

unknown angles are derived:

$$
\tan \psi_{\mathrm{n}}=\frac{\tan \eta \sin \kappa_{\mathrm{r}}}{\cos \lambda_{\mathrm{s}}+\tan \eta \cos \kappa_{\mathrm{r}} \sin \lambda_{\mathrm{s}}} .
$$

The rake angle, $\gamma_{n 0}$, in the normal plane $P_{n}$, at selected point 0 on the cutting edge is defined, according to Fig. 1, from the expression:

$$
\tan \gamma_{\mathrm{n} 0}=\tan \gamma_{\mathrm{p} 0} \frac{\cos \lambda_{\mathrm{s}}}{\cos \kappa_{\mathrm{r}}}-\tan \kappa_{\mathrm{r}} \sin \lambda_{\mathrm{s}}
$$

Accordingly, the tool-in-use rake angle, $\gamma_{\text {ne } 0}$, in the normal plane $\mathrm{P}_{\mathrm{n}}$, at selected point 0 on edge is:

$$
\gamma_{\mathrm{ne} 0}=\gamma_{\mathrm{n} 0}+\psi_{\mathrm{n}} .
$$

The angle $\eta$ is defined in the tool-in-use coordinate system as the feed speed over tangential cutting speed:

$\tan \eta=\frac{v_{\mathrm{s}}}{v}=\frac{P}{\pi d_{0}}$

The relation between angles of the tool-in-hand geometry is:

$\tan \lambda_{\mathrm{s} 0}=\tan \gamma_{\mathrm{p} 0} \sin \kappa_{\mathrm{r} 0}$,

and angle $\gamma_{\mathrm{p} 0}$ as a function of $\gamma_{\mathrm{p}}$ :

$\gamma_{\mathrm{p} 0}=\arcsin \left(\frac{D}{d_{0}} \sin \gamma_{\mathrm{p}}\right)$

where $D, d_{0}$ represent tool diameters.

The oblique angle, $i$, in the tool-in-use cutting edge plane $\mathrm{P}_{\mathrm{se}}$ at selected point 0 on the cutting edge is defined as follows:

$$
\tan i=\frac{\sin \eta \cos \kappa_{\mathrm{r}} \cos \lambda_{\mathrm{s}}-\cos \eta \sin \lambda_{s}}{\sin \eta \sin \kappa_{\mathrm{r}}} \sin \psi_{\mathrm{n}}
$$

\subsection{Influence of minor edges and chamfer angle}

Most often, prediction of tapping forces includes only the action of major edges, but the influence of minor edges is not negligible, especially on the torque. The influence on the axial force is considerably low, assuming symmetry of minor edges relative to the axial plane. The length ratio of minor edges and major edge maximum, for standard ISO profile with the thread angle $\alpha=30^{\circ}$, can be expressed by the expression:

$\frac{l_{\mathrm{p}}}{b_{\mathrm{g} \max }}=\frac{\cos \left(30-\kappa_{\mathrm{r}}\right)}{\tan \kappa_{\mathrm{r}}\left(3 \cdot \cot ^{2} \kappa_{\mathrm{r}}-1\right)} \cdot \frac{10,67}{z}$,

where $l_{\mathrm{p}}$ is the sum of minor edges lengths on a single tooth, $b_{\mathrm{g} \text { max }}$ is the maximal major edge length and $z$ is the number of flutes. The influence of the chamfer angle $\kappa_{\mathrm{r}}$ on this ratio, for the number of flutes $z=3,4$ and 6 is depicted in Fig. 2.

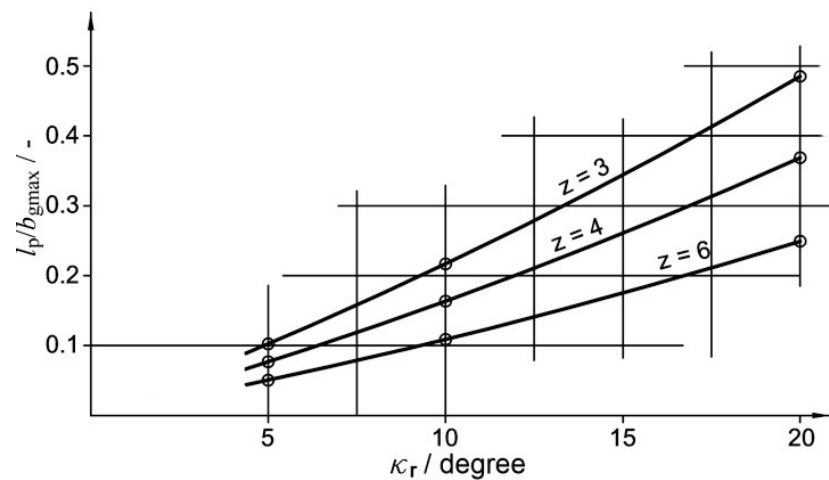

Figure 2 The influence of angle $\kappa_{r}$ on a length ratio of minor and major edges

It is evident form Fig. 2 that the influence of minor edges length increases with the chamfer angle $\kappa_{\mathrm{r}}$. Therefore, at higher $\kappa_{\mathrm{r}}$ values, the length of minor edges can be expected to be higher relative to that of the major edges. This urges the need to study the influence of minor edges in the cutting process and their inclusion in the force model.

\section{Machine taps modelling}

For the straight fluted taps, the major and minor edges can be analytically obtained at cross-sectional surfaces forming them, or by using CAD software packages. In this paper, a class of taps is modelled in the Autodesk Inventor 2011CAD programming environment, using the technique of parametric modelling. In this way, the input into the CAD software is a set of parameters that describe specific dimensions of the taps. One CAD model is created based on tap technology, and works with a number of different sets.

The parameters can be saved in .xml format or spreadsheet software program format. This model uses Microsoft Excel spreadsheet format.xls, which can be defined in similar open-source programs (e.g., Apache 
OpenOffice). The program for preparing a table with the parameters is based on the nominal diameter, tap pitch, and tap type as inputs.

Fig. 3 shows the image of cutting edges of the used machine tap M10 magnified 35 times, and simultaneously displays the image of M10 tap model, obtained by the CAD software using a set of parameters.



Figure 3 The cutting edges of the M10 tap in one flute $(\times 35)$ and the CAD model

Fig. 4 displays the cutting edges along the flutes of the M10 tap with the chamfer angle $\kappa_{\mathrm{r}}=18^{\circ}$, which were obtained in the program package MATLAB using the tap geometry from the CAD package.
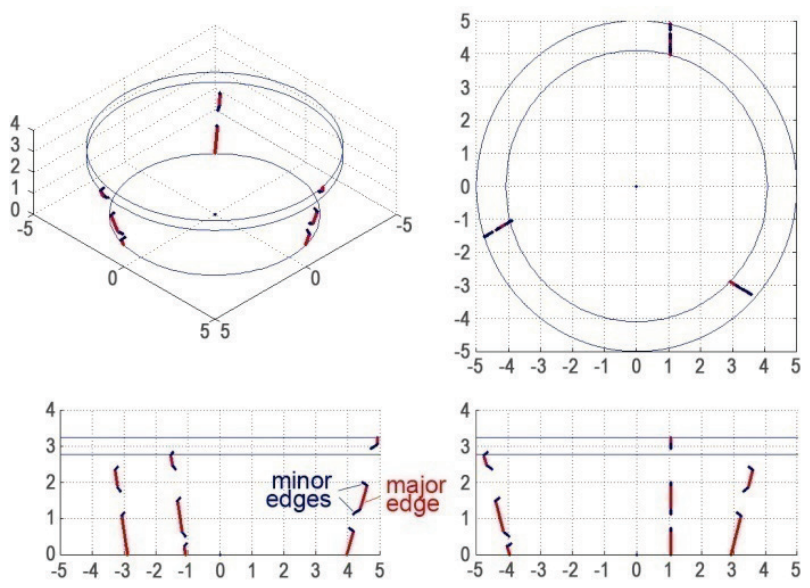

Figure 4 Major and minor cutting edges:M10 tap with $18^{\circ}$ chamfer angle

\section{$4 \quad$ Cutting forces and torque in tapping}

Many studies have shown that the influence of the uncut chip thickness $h$ and chip width $b$ on the cutting force is more significant than the depth of cut $a_{\mathrm{p}}$ and feed $f[4 \div 8]$. For example, in turning, the cross-section of cutting, with the same depth of cut and the feed has a different form, depending on the tool cutting edge angle. Linear force model between the cutting forces and a product of the uncut chip thickness and chip width is commonly used.

The tap is cut into thin slices $(d z)$ perpendicular to the axial direction $[11 \div 13]$. The discretized tap, thin disc, and the directions of cutting forces in tapping are given in Fig. 5.

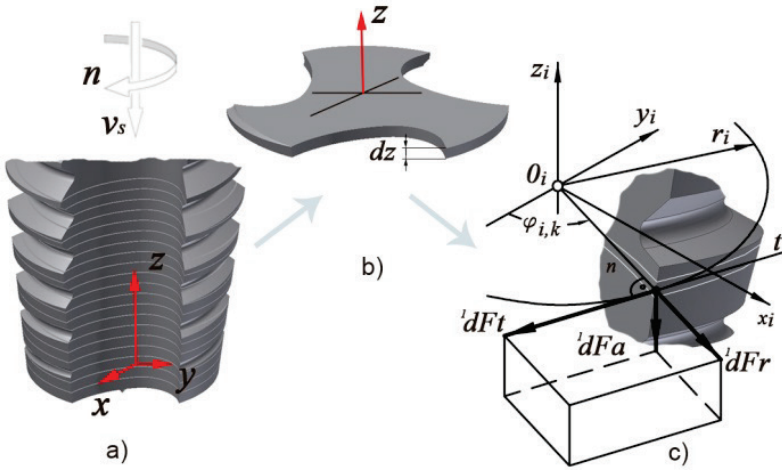

Figure 5 Discretized cutting length of the tap (a), Disc of differential thickness (b), Differential cutting forces in oblique cutting on differential length of the cutting edge (c)

Based on the modified mechanics of cutting analysis $[2,4]$, the three elemental forces $d F_{\mathrm{t}}, d F_{\mathrm{r}}$ and $d F_{\mathrm{a}}$ consist of a "cutting" force component, and an "edge" force component due to rubbing or ploughing at the cutting edge. It is convenient to express the cutting forces in the following form [2]:

$$
\begin{aligned}
& { }^{4} d F_{\mathrm{t}}=K_{\mathrm{tc}} b h+K_{\mathrm{te}} b, \\
& { }^{4} d F_{\mathrm{r}}=K_{\mathrm{rc}} b h+K_{\mathrm{re}} b, \\
& { }^{4} d F_{\mathrm{a}}=K_{\mathrm{ac}} b h+K_{\mathrm{ae}} b,
\end{aligned}
$$

where ${ }^{4} d F_{\mathrm{t}}$ is the cutting force or main force acting in the direction of the cutting velocity, ${ }^{4} d F_{\mathrm{r}}$ is the radial force acting perpendicularly to the machined surface and ${ }^{4} d F_{\mathrm{a}}$ is the axial feed force acting in the direction of the tool travel in the coordinate system "4".

The corresponding cutting force constants are [2]:

$$
\begin{aligned}
& K_{\mathrm{tc}}=\tau_{\mathrm{s}} / C \cdot\left(\cos \left(\rho-\gamma_{\mathrm{n}}\right)+\tan i \tan v \sin \rho\right), \\
& K_{\mathrm{rc}}=\tau_{\mathrm{s}} / C \cdot\left(\cos \left(\rho-\gamma_{\mathrm{n}}\right) \tan i-\tan v \sin \rho\right), \\
& K_{\mathrm{ac}}=\tau_{\mathrm{s}} / C \cdot \cos i \cdot\left(\sin \left(\rho-\gamma_{\mathrm{n}}\right)\right),
\end{aligned}
$$

where $\tau_{\mathrm{s}}$ is the shear stress, $\rho$ represents the average friction angle, $v$ is the chip flow angle and $K_{\mathrm{te}}, K_{\mathrm{re}}, K_{\mathrm{ae}}$ are edge force coefficients in tangential, radial and axial directions. The parameter $C$ is given as follows:

$$
C=\sin \phi_{n} \sqrt{\cos ^{2}\left(\phi_{n}+\rho-\gamma_{n}\right)+\tan ^{2} v \sin ^{2} \rho},
$$

where $\phi_{\mathrm{n}}$ represents shear angle.

Oblique cutting performs the major edge inclined at an angle $\kappa_{\mathrm{r}}$, and two minor edges inclined at an angle $\alpha$ and $-\alpha$, where $\alpha$ is the standard thread angle. The major cutting edges can be found on the conical chamfer surface, while the minor edges are located on the flanks of the threads. Fig. 4 shows the cutting edges on the conical chamfer surface obtained from the machine tap CAD model to determine the cutting edges length and position. Now, applying

${ }^{1} d F=\left[d F_{\mathrm{t}} d F_{\mathrm{r}} d F_{\mathrm{a}}\right]^{\mathrm{T}}={ }_{2}^{1} \boldsymbol{R} \cdot{ }_{3}^{2} \boldsymbol{R} \cdot{ }_{4}^{3} \mathrm{R} \cdot{ }^{4} d F$

the cutting force, $F_{z}$, and torque, $M$, can be evaluated from: 


$$
F_{z}=\sum_{i}^{1} d F_{\mathrm{a}_{i}}, \quad M=\sum_{i}{ }^{1} d F_{\mathrm{t}_{i}} \cdot r_{i}
$$

If we are also interested in calculations in the machine fixed coordinate system, namely forces in two perpendicular directions $F_{x}$ and $F_{y}$ and side force $F_{\text {s }}$, respectively, it is needed, according to Fig. $5 \mathrm{c}$, to perform the transformation into this system as follows:

$$
{ }^{0} \boldsymbol{p}={ }^{0} \boldsymbol{p}_{0}+{ }_{1}^{0} \boldsymbol{R} \cdot{ }^{1} \boldsymbol{p}
$$

where ${ }^{0} \boldsymbol{p}_{0}$ is the position vector of the origin and ${ }_{1}^{0} \boldsymbol{R}$ is the orientation matrix of fixed coordinate system relative to the moving coordinate system.

\subsection{Identification of cutting coefficients}

Cutting coefficients can be found from a database, which usually contains values for limited number of combinations of tool and workpiece materials [7, 8]. For material combinations not supported by a database, simple cutting experiments can provide necessary data [2, $4,12 \div 14]$.

The cutting coefficients can be modelled using either orthogonal cutting mechanics or mechanistic models. In this paper the cutting coefficients were identified using the orthogonal cutting mechanics which was used in predicting the cutting forces and torque. Different methods for determining the influence on cutting surface [15] and the edge forces are discussed by Gonzalo et al. [16] and Popov et al. [17], such as the direct method, the comparison method and the extrapolation method on the zero uncut chip thickness, based on which the forces on the front face do not influence the edge forces.

The cutting process was modelled as a function of work material, tool material and geometry, chip load and cutting speed, by conducting orthogonal cutting tests on the lathe. Experiments are done with cutting fluids switched off. Workpiece was a tube with a $2,1 \mathrm{~mm}$ wall thickness.

In order to obtain cutting coefficients necessary for analysis presented in this work, facing tools featuring diverse rake angles $\left(5 \div 20^{\circ}\right)$ were manufactured using same HSS-E steel (EMo5Co5) as that used for machine taps serial production. The tools had a sharp cutting edge.

Spindle speeds of $5 \div 20 \mathrm{~m} / \mathrm{min}$ and feed rates of $0,01 \div 0,15 \mathrm{~mm} / \mathrm{rev}$ were used. Also, the rake angle is selected within the range of $5 \div 20$ degrees. Feed in orthogonal cutting represents the uncut chip thickness, $h$.

Fig. 6 presents the machining and acquisition systems applied to determine the forces in orthogonal cutting. Cutting forces, main force $F_{1}$ and feed force $F_{2}$, were measured in two directions using a custom made, twocomponent, strain gauge force dynamometer, amplifiers HBM KWS 3082A and NI CompactDAQ acquisition platform (NI USB 9174, NI 9215).

Collection of chip samples was also done in order to calculate its thickness $h_{\mathrm{c}}$ and chip ratio $r_{\mathrm{c}}$. The mean cutting forces from steady-state phase of experiments for constant cutting speed and rake angle are calculated and fitted as a linear function of uncut chip thickness. Fig. 7 shows one of force vs. uncut chip thickness diagram from orthogonal cutting test results, for cutting speed $v=10$ $\mathrm{m} / \mathrm{min}$ and rake angle $\gamma=20^{\circ}$.

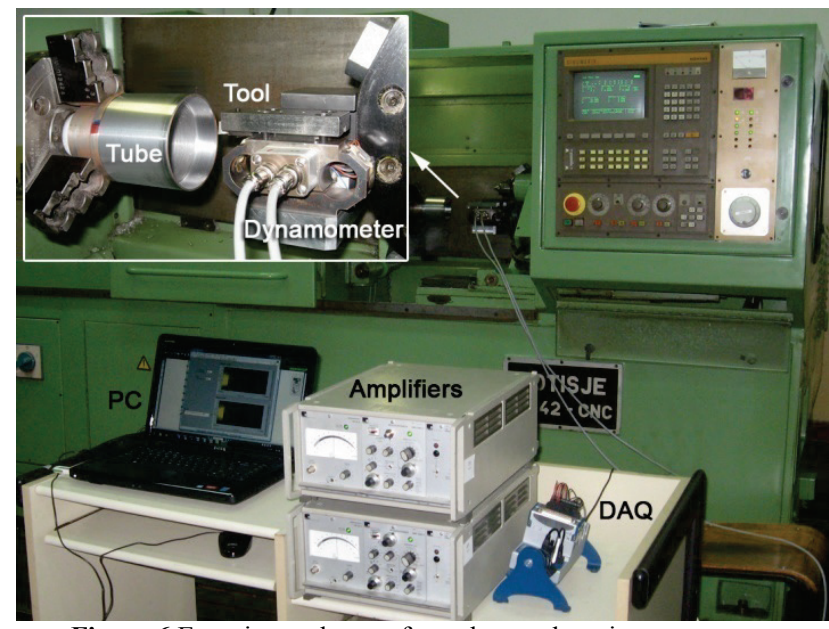

Figure 6 Experimental setup for orthogonal cutting

Parameters $\rho$ and $r_{\mathrm{c}}$, were identified using statistical analysis of data provided from orthogonal cutting tests, while $\tau_{\mathrm{s}}$ was simply averaged for the same series of experimental data. The average edge coefficients $K_{\text {te }}$ and $K_{\text {re }}$ were obtained by means of linear regression and extrapolation of measured forces to zero uncut chip thickness and represent the edge forces per unit width [2, 14]. These results obtained for the material combination of workpiece (16MnCr5) and tool (HSS-E, EMo5Co5) are presented in Tab. 1.

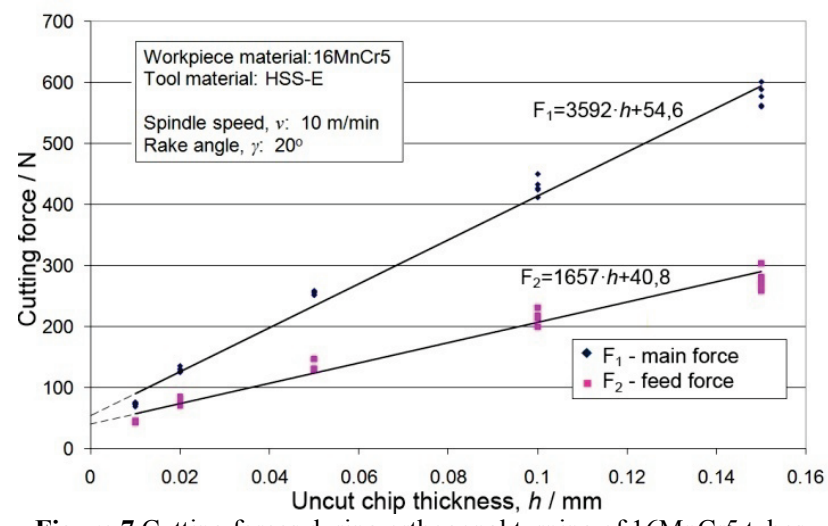

Figure 7 Cutting forces during orthogonal turning of $16 \mathrm{MnCr} 5$ tubes $\left(\nu=10 \mathrm{~m} / \mathrm{min}, \gamma=20^{\circ}\right)$ : measurement and linear regression

Table 1 Orthogonal cutting data based on orthogonal cutting tests

\begin{tabular}{|l|}
\hline$\tau_{\mathrm{s}}=558 \mathrm{MPa}$ \\
\hline$\rho=35,18+0,627 \gamma$ \\
\hline$r_{\mathrm{c}}=C_{0} h C_{1}$ \\
$C_{0}=0,942-0,012 \gamma$ \\
$C_{1}=0,391-0,01 \gamma$ \\
\hline$K_{\mathrm{te}}=28,8 \mathrm{~N} / \mathrm{mm}$ \\
$K_{\mathrm{ae}}=21,5 \mathrm{~N} / \mathrm{mm}$ \\
\hline
\end{tabular}

\subsection{Prediction results}

Tapping forces and torque were predicted using presented equations based on cutting edge geometry along the flutes and experimentally obtained cutting coefficients. The model is performed in program package MATLAB. 
Predicted, through hole tapping axial force and torque for the M10 C type tap (tap pitch $P=1,5 \mathrm{~mm}$, chamfer angle $\kappa_{\mathrm{r}}=18^{\circ}$, and rake angle $\gamma_{\mathrm{p}}=12^{\circ}$ ) with cutting speed $v=5 \mathrm{~m} / \mathrm{min}$ for workpiece-tool material combination $16 \mathrm{MnCr} 5 / \mathrm{EMo} 5 \mathrm{Co} 5$ is presented in Fig. 8.
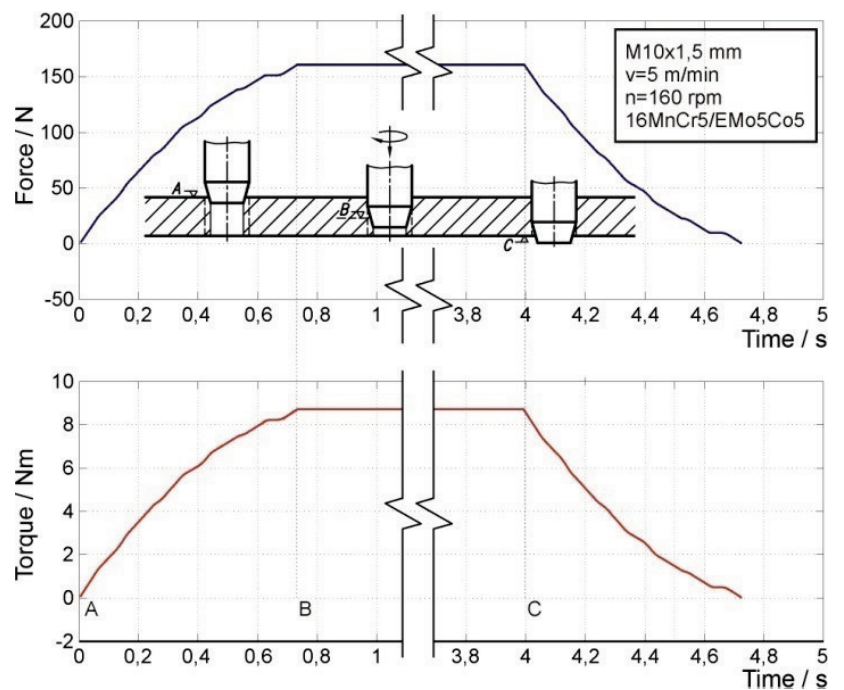

Figure 8 Predicted tapping axial force and torque (M10 tap, $d=8,4 \mathrm{~mm}$, $P=1,5 \mathrm{~mm}, \kappa_{\mathrm{r}}=18^{\circ}, \gamma_{\mathrm{p}}=12^{\circ}, n=160 \mathrm{rpm}$, material combination $16 \mathrm{MnCr} 5 / \mathrm{EMo5Co5})$

During tapping a through hole with straight flute tap, the force and torque are increased as each edge on a chamfer section of the tap enters the operation (A-B, Fig. 8 ) and maximum constant value is reached when all edges are involved in cutting operation (B-C). When chamfer section is disengaged with the workpiece (C-), axial force and torque fall to zero.

\subsection{Experimental verification of prediction}

Experiments were performed on numerically controlled machine tool - horizontal machining centre LOLA HMC500 with no cutting fluids. The experimental setup for tapping is presented in Fig. 9. For the force and torque measurement, a two-component piezoelectric dynamometer Kistler 9271, amplifiers Kistler 5007 and NI CompactDAQ 9174 with module NI 9215 were used.

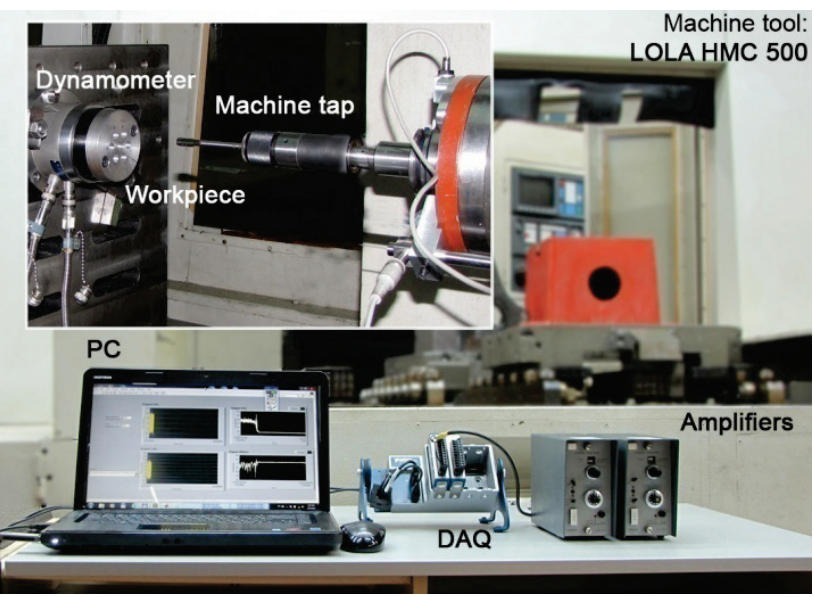

Figure 9 Experimental setup for acquisition of axial force and torque during the tapping cycle
Measured axial force and torque and predicted values for equal conditions are presented in Fig. 10, for M10 C type tap with metric normal profile. Measurement signal was filtered using cubic smoothing spline to reduce axial cutting force and torque dynamics component. Geometric and process parameters used for experimental model verification are listed in Tab. 2. Taps are with three straight flutes. The workpiece-tool material combination was $16 \mathrm{MnCr} 5 /$ EMo5Co5. Cutting speed was $5 \mathrm{~m} / \mathrm{min}$, and through hole depths were $15 \mathrm{~mm}$.

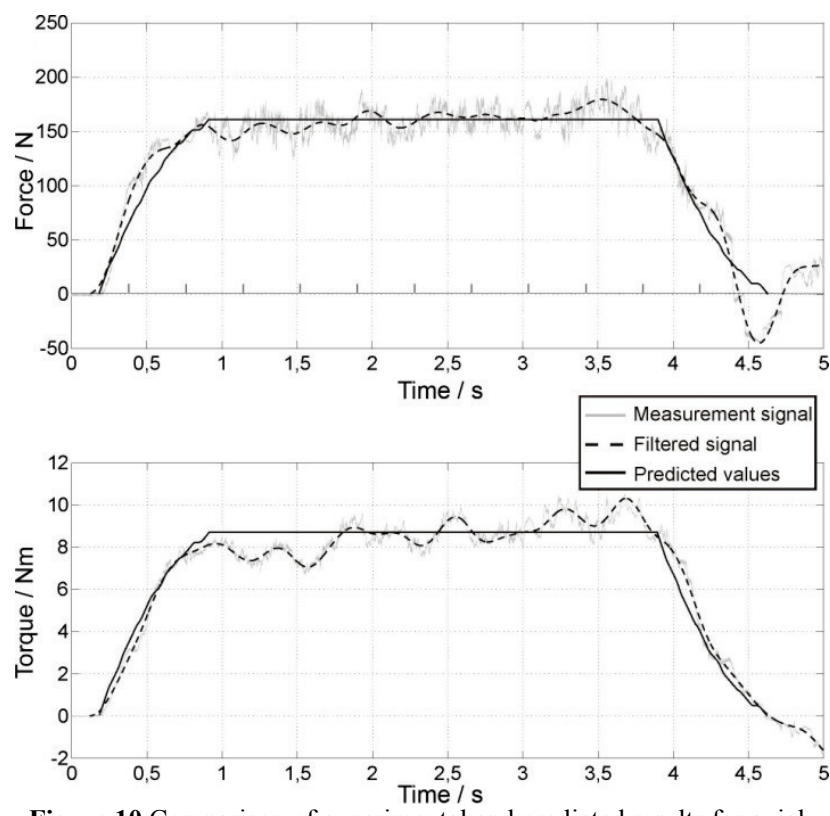

Figure 10 Comparison of experimental and predicted results for axial force and torque during the M10 tapping operation

Table 2 Geometric and process parameters used for experimental model

\begin{tabular}{|l|c|c|}
\multicolumn{1}{|c|}{ Description } & Unit & Value \\
\hline Tap material & & HSS-E, EMo5Co5 \\
\hline Nominal diameter & $\mathrm{mm}$ & 10 \\
\hline Pitch & $\mathrm{mm}$ & 1,5 \\
\hline Chamfer length & $\mathrm{mm}$ & 2,9 \\
\hline Rake angle & $\mathrm{deg}$ & 12 \\
\hline Number of flutes & - & 3 \\
\hline Workpiece material & & $16 \mathrm{MnCr} 5$ \\
\hline Premachined hole diameter & $\mathrm{mm}$ & 8,4 \\
\hline Through hole length & $\mathrm{mm}^{-1}$ & 15 \\
\hline Spindle speed & $\mathrm{min}^{-1}$ & 160 \\
\hline
\end{tabular}

Axial force and torque measurement signals slightly increase during constant predicted values, as the influence of tap calibrating section friction effects. Overall, a good agreement is obtained. The deviations between experimental and simulation results are expected, however satisfactory, being within the range of $10 \%$. It is experimentally proven that this model can be used in predicting the tapping forces and torque. The complexity of real tapping process and resulting cutting forces exceed somewhat the capabilities of proposed numerical model. Observed inaccuracy of the model applied in this study comes predominantly from experimentally provided cutting coefficients used for force calculation. Effects of coolant and cooling process, tapping axis position, deviations of diameter of previously machined holes, tool 
holder features and many other factors not taken into consideration affect results of modelling as well.

\section{Conclusion}

A model for the prediction of tapping forces and torque is developed in this research. In addition to the effects of the major cutting edges, this model includes an action from minor cutting edges of the machine tap. The forces and torque acting on a cutting tool during the process are of fundamental importance in the design of cutting tools and evaluation of the performance of new workpiece and tool materials.

Acceptable results, experimentally confirmed and evaluated, were achieved by the prediction related to taps with straight flutes. For the applied workpiece-tool material combination (16MnCr5 / EMo5Co5), the deviations between the predicted and measured values were within the $10 \%$ range, which indicates that the developed model can be effectively used to predict the forces and torque for the tapping process. Using this model, substantial time and cost savings can be obtained.

The parameters identified for a specific combination of workpiece and tool material and presented in Tab. 1, were used to simulate the process of tapping, can be used to simulate any other cutting process. In such a case, it is only necessary to perform a geometry analysis of the new cutting tool.

\section{References}

[1] Shaw, M. C. Metal Cutting Principles. $2^{\text {nd }}$ ed. Oxford University Press, 2005

[2] Altintas, Y. Manufacturing Automation. Cambridge University Press, UK, 2012.

[3] Patel, H.; Patel, B.; Patel, S. A review on Thread Tapping Operation and Parametric Study. // International Journal of Engineering Research and Applications. 2, 3(2012), pp 109-113.

[4] Armarego, E. J. A. The Unified-Generalized Mechanics Of Cutting Approach - A Step Towards A House Of Predictive Performance Models For Machining Operations. // Machining Science and Technology. 4, 3(2000), pp. 319362. DOI: $10.1080 / 10940340008945715$

[5] Cao, T.; Sutherland, J. W. Investigation of thread tapping load characteristics through mechanistic modeling and experimentation. // International Journal of Machine Tools \& Manufacture. 42, (2002), pp. 1527-1538. DOl: 10.1016/S0890-6955(02)00108-6

[6] Dogra, A. P. S.; Kapoor, S. G.; DeVor, R. E. Mechanistic Model for Tapping Process with Emphasis on Process Faults and Hole Geometry. // Journal of Manufacturing Science and Engineering. 124, (2002), pp. 18-25. DOI: 10.1115/1.1430237

[7] Armarego, E. J. A.; Chen, M. N. P. Predictive Cutting Models for the Forces and Torque in Machine Tapping with Straight Flute Taps. // Annals of the CIRP. 51, 1(2002), pp. 75-78. DOI: 10.1016/S0007-8506(07)61469-3

[8] Chen, N. M.; Smith, A. J. R. Modelling of Machine Tapping with Straight Flute Taps. // Proceedings of the $36^{\text {th }}$ International MATADOR Conference / Manchester, 2010 pp. 189-192. DOI: 10.1007/978-1-84996-432-6_43

[9] ISO 3002/1. Geometry of the Active part of Cutting Tools. Part I: General Terms, Reference Systems, Tool and Working Angles, Chip Breakers, 1982.
[10] Slavkovic, N. at al. Cartesian Compliance Identification and Analysis of an Articulated Machining Robot. // FME Transactions. 41, 2(2013), pp. 83-95.

[11] Altintas, Y.; Brecher, C.; Weck, M.; Witt, S. Virtual Machine Tool. // CIRP Annals-Manufacturing Technology. 54, 2(2005), pp. 115-138. DOI: 10.1016/S0007-8506(07)600225

[12] Kokotovic, B.; Glavonic, M. Predicting of milling forces in a virtual manufacturing system. // Tehnicki vjesnikTechnical Gazette. 20, 6(2013), pp. 1027-1035.

[13] Adem, K. A. M.; Fales, R.; El-Gizawy, A. S. Identification of cutting force coefficients for the linear and nonlinear force models in end milling process using average forces and optimization technique methods. // Int J Adv Manuf Technol. 79, 9-12(2015), pp. 1671-1687. DOI: 10.1007/s00170-015-6935-3

[14] Budak, E.; Altintas, Y.; Armarego, E. J. A. Prediction of Milling Force Coefficients from Orthogonal Cutting Data. // Journal of Manufacturing Science and Engineering. 118, (1996), pp. 216-224. DOI: 10.1115/1.2831014

[15] Krolczyk, G.; Legutko, S.; Stoić, A. Influence of cutting parameters and conditions onto surface hardness of Duplex Stainless Steel after turning process. // Tehnicki vjesnikTechnical Gazette. 20, 6(2013), pp. 1077-1080.

[16] Gonzalo, O.; Beristain, J.; Jauregi, H.; Sanz, C. A method for the identification of the specific force coefficients for mechanistic milling simulation. // International Journal of Machine Tools \& Manufacture. 50, (2010), pp. 765-774. DOI: 10.1016/j.jijmachtools.2010.05.009

[17] Popov, A.; Dugin, A. Effect of uncut chip thickness on the ploughing force in orthogonal cutting. // Int J Adv Manuf Technol. 76, (2015), pp. 1937-1945. DOI: 10.1007/s00170014-6423-1

\section{Authors' addresses}

Mihajlo Popović, MSc (ME)

University of Belgrade, Faculty of Mechanical Engineering, Department for Production Engineering,

Kraljice Marije 16, 11120 Beograd 35, Republic of Serbia E-mail: mpopovic@mas.bg.ac.rs

\section{Antun Stoić, PhD, Full. Prof.}

Faculty of Mechanical Engineering in Slavonski Brod,

J. J. Strossmayer University of Osijek,

Trg Ivane Brlić Mažuranić 2, HR-35000 Slavonski Brod, Croatia

E-mail: astoic@sfsb.hr

\section{LjubodragTanović, PhD, Full. Prof.}

University of Belgrade, Faculty of Mechanical Engineering, Department for Production Engineering,

Kraljice Marije 16, 11120 Beograd 35, Republic of Serbia E-mail: 1tanovic@mas.bg.ac.rs 